
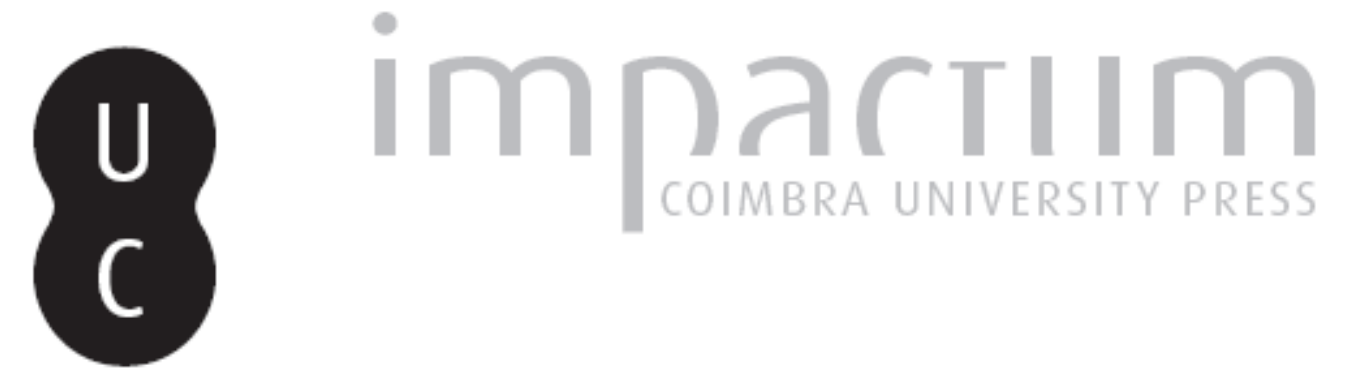

\title{
¿Quién es y qué enseña el Calicles de Platón?
}

\section{Autor(es): Bravo, Francisco}

Publicado por: Annablume Clássica

URL persistente:

URl:http://hdl.handle.net/10316.2/24319

DOI:

DOI:http://dx.doi.org/10.14195/1984-249X_10_3

Accessed : $\quad$ 26-Apr-2023 05:18:33

A navegação consulta e descarregamento dos títulos inseridos nas Bibliotecas Digitais UC Digitalis, UC Pombalina e UC Impactum, pressupõem a aceitação plena e sem reservas dos Termos e Condições de Uso destas Bibliotecas Digitais, disponíveis em https://digitalis.uc.pt/pt-pt/termos.

Conforme exposto nos referidos Termos e Condições de Uso, o descarregamento de títulos de acesso restrito requer uma licença válida de autorização devendo o utilizador aceder ao(s) documento(s) a partir de um endereço de IP da instituição detentora da supramencionada licença.

Ao utilizador é apenas permitido o descarregamento para uso pessoal, pelo que o emprego do(s) título(s) descarregado(s) para outro fim, designadamente comercial, carece de autorização do respetivo autor ou editor da obra.

Na medida em que todas as obras da UC Digitalis se encontram protegidas pelo Código do Direito de Autor e Direitos Conexos e demais legislação aplicável, toda a cópia, parcial ou total, deste documento, nos casos em que é legalmente admitida, deverá conter ou fazer-se acompanhar por este aviso.

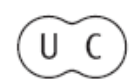



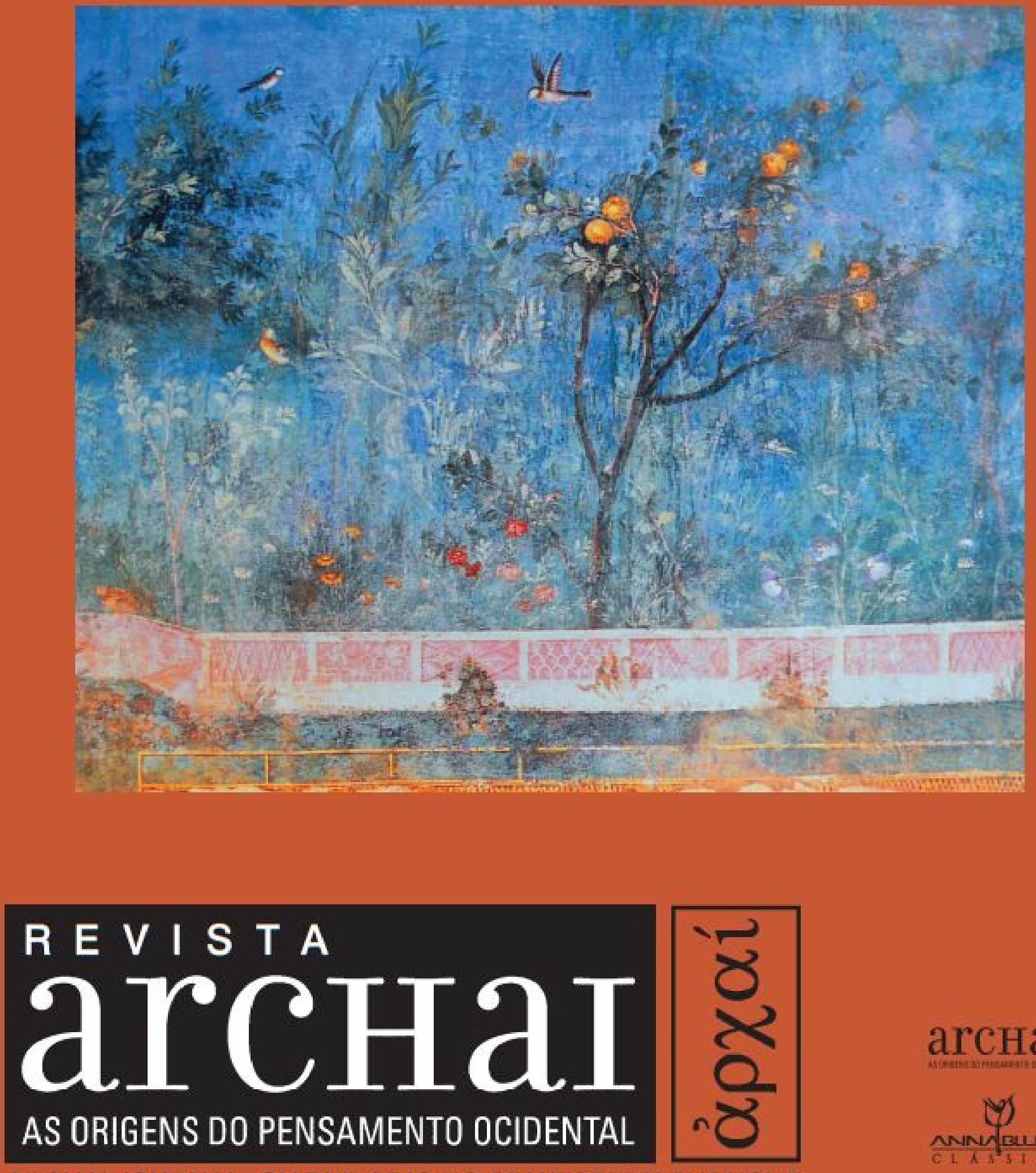

arcнаI

ARCHAI JOURNAL: ON THE ORIGINS OF WESTERN THOUGHT

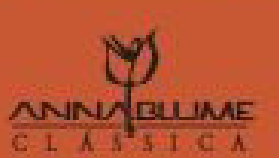




\section{¿QUIÉN ES Y QUÉ ENSEÑA EL CALICLES DE PLATÓN?}

BRAV0, F. (2013). ¿Quén es y qué enseña el Calicles de Platón? Archai, n. 10, jan-jul, p. 29-36.

RESUMEN: Calicles es, sin duda, el personaje platónico que mayor autonomía ha alcanzado respecto de su autor y más ha influido en ciertas corrientes filosóficas contemporáneas. Es, en realidad, significativo que su influencia se sienta aún en nuestra época. Como escribía Dodds en 1959, es una extraña ironía de la historia que la exposición hecha por Platón de ideas que intentaba destruir haya contribuido a su formidable renacimiento en nuestros días. No carece, pues, de interés re-examinar la identidad de este personaje y las doctrinas que defiende. ¿Quién es? ¿Qué enseña? ¿Qué intenta Platón al ponerlo en escena? Puesto que es conocido sólo por el Gorgias, no sería plausible responder a la pregunta "quién es" antes de determinar al menos lo esencial de "qué enseña".

TÉRMINOS-CLAVE: Calicles, enseñanza, justicia, derecho del más fuerte.

ABSTRACTS: Callicles is perhaps the platonic character who has reached the greatest autonomy from his author and the one who has the more influenced some contemporary threads of thought. It is indeed significant that his influence is still sensible in our time. As Dodds wrote in 1959, it is a curious irony of history that an exposition by Plato of ideas that he intended to demolish had contributed to their redoubtable revival in present days. It is thus interesting to examine again the identity of this personage and the doctrines he maintained. Who then is Callicles? What does he teach? What did Plato aim through his performing? As he is known only from Plato's Gorgias, we must answer first to
1. Professor da Universidad Central da Venezuela.

2. Kerferd, (1981) 119 . 3. Gorgias $483 \mathrm{~d} 1-3$ y 6

4. Gorg. 483 e 4 .

5. Gorg. 483 e 5 .
Francisco Bravo ${ }^{1}$

\section{CALICLES Y LA TESIS DEL DERECHO DEL MÁS FUERTE}

Las "doctrinas" de Calicles van de la filosofía al hedonismo ético extremo, pero el eje de todas es su teoría de la justicia. Los intérpretes concuerdan en que ésta no es un puro invento de Platón, sino un reflejo de las doctrinas que bullían en la época. Pero el autor no se limita a registrarlas: los argumentos que esgrimen sus personajes, Calicles en particular, son, como observa G.B. Kerferd", "compuestos y manipulados" por él, y podemos decir, al respecto, que "él es el productor, el gerente de producción y el autor del guión".

La tesis fundamental de nuestro personaje con respecto a la vida justa es que ella consiste en que el más fuerte prevalezca sobre el más débil y tenga más que él ${ }^{3}$. Así lo mostrarían, en la historia griega reciente, las acciones de Jerjes, quien había invadido Grecia sin otro fundamento que su poderío, y las de Darío, su padre, quien había subyugado a los débiles escitas con títulos de la misma índole. Según Calicles, ambos han procedido "en conformidad con la naturaleza de lo justo (katà physin tên toû dikaiou $)^{\prime \prime}$, que, en cuanto tal, es "ley de la naturaleza (nómon tês phýseôs)" ${ }^{{ }^{5}}$, aunque se oponga a las leyes de la ciudad. Distingue, pues, la ley natural y 
the question "who is he" before establishing at least the essential of "what he does teach".

KEY-WORDS: Callicles, teaching, justice, right of the stronger.

las leyes del Estado y sostiene que sólo la primera se identifica con la naturaleza de lo justo, mientras que las otras son "normas contrarias a la naturaleza (mómous toús parà phýsin hápantas) ", por lo cual éstas y aquéllas "lo más a menudo se contradicen entre sí (enantíallêlois estín)" ${ }^{\prime{ }^{7}}$.

Recordemos, sin embargo, que aún no era claro en esa época lo que es una ley estatal. “Se da el nombre de ley - responde Pericles a la pregunta de Alcibíades - a toda decisión de la Asamblea del Pueblo, hecha constar por escrito, en la que se determina lo que se debe hacer o no hacer" ${ }^{\prime \prime}$. Similar es la respuesta de Sócrates a Hipias: las “leyes del Estado son contratos o pactos hechos por los ciudadanos, mediante los cuales han establecido y promulgado qué es lo que se debe hacer y qué es lo que se debe evitar" ${ }^{\prime 9}$. En ambas descripciones, las leyes estatales son convenciones de los ciudadanos "sobre lo que debe tener validez entre ellos" ${ }^{10}$. Son, pues, subjetivas y varían de una ciudad a otra ${ }^{11}$. Pero Calicles aclara que ellas no son lo que aprueba toda la ciudad, sino lo que aprueba la multitud, pues los hombres sabios se atienen a lo que es conforme con la naturaleza y la verdad ${ }^{12}$. Abraza, así, de lleno la antítesis nómos - phýsis, introducida probablemente por Arquelao ${ }^{13}$ y ampliamente debatida en los siglos $\mathrm{V}$ y IV ${ }^{14}$. Más aún, algunos ${ }^{15}$ creen que Calicles ofrece una concepción original de la misma; y parecen tener de su lado a Aristóteles, quien la vincula con nuestro personaje ${ }^{16}$, observando que, "para estos filósofos, lo que es según la naturaleza es la verdad (tò alêthés) y lo que es según la ley opinión de la multitud (tò tois polloîs dokoûn $)^{\prime \prime^{17}}$. Pero no faltan quienes creen que Calicles no hizo más que "reproducir las ideas fundamentales de Hipias" ${ }^{18}$. En contra de ellos, otros opinan que el iusnaturalismo de Hipias es esencialmente distinto del iusnaturalismo calicliano. Recordemos las palabras que el Protágoras ${ }^{19}$ pone en labios del sofista de Elide: “A todos los aquí presentes -dice- os considero como hermanos, como prójimos, como conciudadanos según la naturaleza (phýsei), aunque no según la ley (ou nómoi). Según la naturaleza, en efecto, lo semejante es pariente de lo semejante, pero la ley, tirana de los hombres (týrannos tôn anthrôpôn), hace violencia a la naturaleza" ${ }^{\prime 20}$. Como se ve, también Hipias critica la ley positiva en nombre de la ley natural, al igual que Calicles. Pero no niega su validez como éste. Propugna más bien "un derecho de categoría superior, una ley no escrita" ${ }^{21}$ que nombra explícitamente en su diálogo con el Sócrates de Jenfonte ${ }^{22}$ y que atribuye a los dioses ${ }^{23}$. Su iusnaturalismo adopta, de este modo, una dirección cosmopolita, democrática y humanitaria, compatible con la ley escrita, aunque superior a ella. Calicles sostiene, en contraste, que todas las leyes positivas son "contrarias a la naturaleza (parà phýsin hápantas ${ }^{24}$ )", y un invento de los débiles para domesticar a los más fuertes, cultores de la ley de la naturaleza (katà nómon ge tês phýseôs ${ }^{25}$ ). Los débiles, en efecto, valiéndose del proceso educativo, se apoderan de los fuertes desde su más tierna edad, como si fueran unos leonzuelos (hôsper léontas) que hay que domar, y los modelan a fuerza de encantamientos, hasta hacerles creer que "hay que tener igual que los otros (tò ison chrê échein)" y que "en ello consiste lo bello y lo justo" ${ }^{26}$, a tenor de la democracia ateniense.

Ésta es, en realidad, el blanco de los ataques de Calicles, mientras que para Protágoras, uno de sus propulsores más antiguos, ella es "la única forma de gobierno justificable ${ }^{\prime 27}$. Según el “Mito de Protágoras", las ciudades mismas se hicieron posibles gracias a que Hermes, enviado de Zeus, trajo a los hombres "el pudor y la justicia (aidô te kaì díkên ${ }^{28}$ )" y los distribuyó, no a uno o a unos pocos, como el arte de la música, sino "a todos" por igual (epi pántas ${ }^{29}$ ), como primera condición de posibilidad de la vida en sociedad, que es la verdadera vida humana ${ }^{30}$. La conclusión de este manifiesto protagórico de la democracia no pudo ser más tajante: “quien sea incapaz de participar de estos dones será condenado a muerte, como una plaga para la ciudad" (322d45). Según el sofista de Abdera, los atenienses creen firmemente que "todos los hombres participan de la justicia" ${ }^{31}$. Para Heródoto, estrechamente vinculado con él, "la democracia es el mundo de la igualdad
6. Gorg. 484 a 6 .

7. Gorg. 482 e 7-8.

8. Jenofonte, Mem. I, 2, 40

9. Jenofonte, Mem. IV, 4 .

10. Menzel (1964) 28.

11. Es una convicción en que coinciden Calicles y Protágoras. Cf. Teet., 177 d 1-4 y 172a-c. 12. Cf. Menzel (1964) 26. Este autor observa que Calicles asimila la physis a la razón, identificando así el derecho natural con el derecho racional. Ahora bien, esta idea alcanzó un desarrollo pleno sólo en los estoicos. A través de Cicerón, ella se impuso en la filosofía del derecho de la Edad Media y la Época Moderna.

13. Diog. L., II, 16.

14. Cf. Bravo (2001: 15-42).

15. Menzel (1964) 25.

16. Aristóteles, Soph. Elench.

173 a 2 ss.

17. Soph. Elench. 173 a 16 18. Cf. F. Dümmler, Academica, Huyesen, 1889, cit. por Menzel (1964) 30.

19. Cf. Prot. 337c-338b.

20. Prot. 337c7-d2.

21. Menzel (1964) 30.

22. Mem. IV, 4 : “ ${ }^{\prime} i$ sabes lo que significa la expresión “leyes no escritas"? -"Sí, las que son uniformemente observadas en todo país".

23. Mem. IV, 4: "Creo que los dioses hicieron estas leyes para los hombres".

24. Gorg. 484 a 5 .

25. Gorg. 483 e 5 .

26. Gorg. 484 a 1-3.

27. Cf. Menzel (1964) 10.

28. Prot. 322 c 2.

29. Prot. $322 \mathrm{~d} 1$.

30. Del "Mito de Protágoras" se sigue que, contrariamente a lo defendido por Calicles, "el estado de naturaleza es una vida sin derecho, sin moralidad y sin Estado". La conclusión es que lo justo "no existe por naturaleza, pues se da únicamente en las leyes aprobadas por el pueblo". Cf. Menzel (1964) 17-18.

31. Prot. 323c1. Es lo que se desprende de la traducción de A. Croiset, Col. Budé, 1967. 
32. Citado por Menzel (1964) 10 33. Cf. Menzel (1964) 12, 14 34. También Demócrito defiende el pensamiento jurídico democrático y la idea del Estado igualitario. Para él, la democracia presupone la armonía (ĐmÒnoia) de los ciudadanos. Cf. DK B 251.

35. En las Suplicantes y las Fenicias de Eurípides hay hermosas alabanzas a la democracia. En la primera de estas obras, Teseo consiente, a petición de su madre, en rescatar los cadáveres de los héroes caídos; pero desea "se aprobado por el conjunto de

pueblo (...)". "Porque -dice- yo he hecho de él un Estado soberano donde todos son libres y tienen los mismos derechos" (349-352) Y dirigiéndose al heraldo de Tebas le advierte que "nuestra ciudad no está en poder de un solo hombre. Es su pueblo quien la gobierna. El dinero no tiene ningún privilegio.

El pobre y el rico tienen los mismos derechos" (404-408). Menzel (1964) 14 cree que estas dos tragedias pueden considerarse

"como modelos literarios" del Discurso de Pericles.

36. Tucíd. II, 1, 37; cf. Menze (1964) 12. 37. Tucíd. II, 1, 37. 38. Gorg. 484 b 1. 39. No es distinto el mensaje fundamental de Zaratustra: "Ich lehre euch den Übermenschen. Der Mensch ist etwas, das überwunden werden soll". (F. Nietzsche, Also sprach Zarathustra, Prólogo, 3).

40. El Banquete (177b3) de Platón recuerda que Heracles ha sido objeto de elogios por parte de algunos "sofistas de valor". Piensa, sin duda, en el ensayo Sobre Heracles, de Pródico, referido por Jenofonte, Mem. I 21-34. Eurípides lo considera como "el más grande de los héroes ( $L a$ locura de Heracles, 150). 41. Gigante con tres cabezas tres cuerpos hasta las caderas, que habitaba en la isla de Eristia, situada en las brumas de occidente. Su riqueza consistía en rebaños de bueyes guardados po el boyero Euritión, acompañado de su perro Orto (u Ortro). Cf. P. Grimal (1994: 213) 42. Gorg. $484 \mathrm{c} 2$

43. Platón parece aceptar esta interpretación de los versos del autor de los Epinicios. Pero ella parece unilateral e incompleta, pues -como observa Menzel (1964) 51 - "olvida el momento religioso de la solución". En efecto, "la victoria de Heracles sobre el gigante Geriones no es un simple resultado de la mayor fuerza, sino

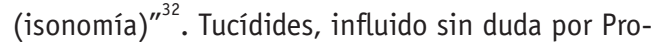
tágoras $^{33}$, por Demócrito ${ }^{34}$ e incluso por Eurípides ${ }^{35}$, puso en labios de Pericles el principio fundamental del Estado democrático: “sirve -dice- a los intereses de la masa de los ciudadanos y no sólo a los de una minoría $^{\prime 36}$. Y enuncia luego, como sus elementos fundamentales, la igualdad, la libertad y el imperio de la ley. Sobre todo la igualdad, proclamando que “todos somos iguales ante la ley" ${ }^{\prime 37}$. Es el principio que Calicles intentaba destruir.

Supóngase, dice, que, de entre los domesticados por la democracia surge "un hombre suficientemente bien dotado por la naturaleza como para sacudir (...) y lanzar lejos de sí todas las cadenas": "estoy seguro -sostiene- que, arrojando a sus pies nuestros escritos, sortilegios y encantamientos", éste, quien era antes nuestro esclavo (doàloj), se sublevaría y se erguiría como nuestro amo (despótês hêméteros). Y brillaría entonces en todo su esplendor lo justo por naturaleza (tò tês phýseôs díkaion)" ${ }^{\prime 38}$. Así, al principio de la democracia igualitaria opone Calicles la necesidad del superhombre, condición de posibilidad de la justicia natural ${ }^{39}$.

\section{LOS ALIADOS DE CALICLES}

En apoyo de su iusnaturalismo anti-igualitario, Calicles invoca una oda de Píndaro que expresa -dice- "el mismo pensamiento que yo cuando afirma que la ley, reina de todas las cosas (nómos hĐ pántôn basileýs), / justifica la fuerza que conduce todo / con su mano soberana". Y la ilustra con una hazaña de Heracles, el modelo griego del superhombr ${ }^{40}$. Éste, sin haber pagado por él ni haberlo recibido como un don, se apodera de un rebaño de bueyes de Geriones ${ }^{41}$, alegando que, según "la justicia por naturaleza, los bueyes y todos los bienes del más débil y menos valiente son propiedad del mejor y más fuerte" ${ }^{\prime{ }^{42}}$. Así, Píndaro habría visto la ley natural realizada en la hazaña de Heracles y sido, con ello, uno de los primeros griegos en defenderla ${ }^{43}$. Calicles, por su lado, se sirve de este mito pindárico para postular, por primera vez, el advenimiento del super-hombre como única vía para restaurar la ley de la naturaleza ${ }^{44}$. Por curioso que parezca, Platón y Aristóteles no parecen ajenos a esta figura. Sería, en efecto, legítimo ver cierta similitud entre el superhombre de Calicles y el gobernante-filósofo del estado platónico ${ }^{45}$. El Estagirita, por su lado, no descarta la hipótesis de un individuo o grupo de individuos que, por su virtud trascendente, lleguen a ser como un dios entre los hombres (hôsper gàr theón en anthrôpois) ${ }^{46}$. Para estos "superhombres" ${ }^{47}$ -sostiene- no hay ley, sino que ellos mismos son la ley ${ }^{48}$, y sería ridículo legislar para ellos, pues replicarían con las palabras que Antístenes pone en boca de los leones cuando las liebres reclaman igualdad para todos ${ }^{49}$.

Volvamos a Platón. Además de su tesis del filósofo-rey, que puede evocar al superhombre de Calicles, hay, en los diálogos, otros personajes que parecen transitar la misma vía que nuestro personaje. $Y$ ante todo Trasímaco ${ }^{50}$, cuya tesis fundamental es que lo justo no es otra cosa que lo útil al más fuerte (toû kreítonos xymphéron ${ }^{51}$ ). De ella concluye, sin embargo, contrariamente a Calicles, que el único derecho es el positivo ${ }^{52}$, determinado, en cada caso, por la utilidad del más fuerte ${ }^{53}$. A primera vista, se opone a nuestro personaje, pues excluye lo justo por naturaleza. Pero coincide con él en que el derecho positivo no ampara a todos los ciudadanos, sino únicamente a los más fuertes ${ }^{54}$. Otro personaje que se le acerca es Glaucón, escogido para exponer la doctrina de algunos sofistas, especialmente de Trasímaco ${ }^{55}$. ¿Por qué dio Platón este encargo a su hermano? Tal vez -dice Menzel- "por la misma razón por la que creó la figura de Calicles, con cuyo pensamiento está Glaucón íntimamente emparentado" ${ }^{\prime 56}$. Ante los inconvenientes que acarrean, tanto cometer la injusticia como sufrirla, él sostiene que lo más conveniente ha sido establecer convenios mutuos para evitar uno y otro (xýnthésthai allêlois mêt' adikeîn mêt' adikeîsthai ${ }^{57}$ ). De estos convenios "nacieron las leyes y las convenciones de los hombres entre sí", de modo que ellos constituyen "el origen y la esencia de la justicia" (359a5), punto medio (metaxý) entre el mayor bien - la injusticia impune- y el mayor mal -“la impotencia para vengarse de" ella (359a6-7). Como se ve, Galucón no se limita a comentar a Trasímaco: para éste, la ley es una imposición del más fuerte, mientras que para aquél es el fruto de un contrato. Esta tesis hace de él, como observa Menzel, 
“el precursor de la idea del contractus socialis" ${ }^{\prime 58}$. Coincide, sin embargo, con Calicles en que el orden jurídico positivo favorece sólo a los muchos débiles y no a los pocos "hombres de verdad" (alêthôs ándra59), que son los superhombres. Son inequívocamente caliclianas estas declaraciones suyas, al comienzo del relato del anillo de Giges: "el justo sigue el mismo camino que el injusto, pues, como él, es arrastrado por el incesante deseo de tener más (dià tên pleonexían), que toda naturaleza persigue como un bien (ho pâsa phýsis diôkein péphyken ôs agathón) y que la ley desvía, por la fuerza, hacia el respeto de la igualdad" ${ }^{60}$.

\section{III. ¿QUIÉN ES EL MÁS FUERTE?}

La convicción de Calicles es que Sócrates aceptaría su tesis si renunciara a su concepción de la filosofía y aceptara la suya ${ }^{61}$. No es mi intención exponer esta última, afín a la de Isócrates en varios puntos $^{62}$, ni analizar minuciosamente la refutación socrática de su tesis central ${ }^{63}$. Me atendré únicamente a lo que Sócrates pone en el centro del debate, a saber, el concepto de 'más fuerte' (tò kreîtton). Lo que el vocero de Platón intenta demostrar es que los muchos débiles pueden ser más fuertes que los pocos fuertes. ¿Pero qué entiende Calicles por ‘tò kreîtton (el más fuerte)'? ¿Significa lo mismo que 'tò béltion'(el mejor)? (488b9) ¿Puede ocurrir que lo mejor se asocie con lo más débil? (488c7). La respuesta negativa de Calicles hace que su oponente objete que, en la realidad de los hechos, la multitud (hoi pólloi) es naturalmente más fuerte y mejor que el individuo (toû henós). Es, en efecto, ella "quien le impone sus leyes" (488d6-7), que son, por consiguiente, "leyes del poderoso" (488d7). Ahora bien, la multitud sostiene, contrariamente a Calicles, que “la justicia consiste en la igualdad (díkaion eînai tò íson échein)" y no en la desigualdad y que, por tanto, "cometer la injusticia es más feo que sufrirla" (489a3-4). Nuestro iusnaturalista anti-igualitario no puede menos que admitir que, efectivamente, "esto es lo que piensa la multitud" (489a8). Esta concesión permite a su oponente concluir que el principio según el cual cometer la injusticia es más feo que sufrirla es conforme, no sólo con la ley (positiva: nómoi), sino también con la naturaleza (phýsei), y que, por tanto, es falso que la ley y la naturaleza sean contrarias entre sí (489b2-3). Ante el riesgo de una palinodia no deseada, Calicles pretende que lo que ha dicho es que 'mejor' y 'más fuerte' son (...) sinónimos (489c2-3), pero no en el plano de las gentes sin valor, sino en el de los fuertes. Esta irritada escapatoria permite a Sócrates concluir que, para su oponente, pese a lo que ha dicho, 'mejor' no es sinónimo de 'más fuerte' (489d4). ¿Qué entiende, pues, por 'mejores'? (ti pote legéis toùs beltíous;)? ¿"quiénes son los mejores"?

Calicles acoge esta sugerencia con cierto entusiasmo y acomoda a ella su tesis del derecho del más fuerte: “lo justo según la naturaleza -dice ahora- es que el mejor, es decir, el más razonable, gobierne a los mediocres y tenga más que ellos" (490a7-8). Y reitera que el mejor es el más sabio (tò phronimôteron beltío: 490d2). ¿En qué orden de cosas (per^ t...nwn: 491a4)?, pregunta su oponente. No en el de las manualidades, sino en el concerniente a los asuntos políticos. Los mejores son, pues, quienes se dedican a ellos y son sabios y valientes en su gestión (491c6-7). Pero queda por determinar si los mejores se gobiernan también a sí mismos (autòn heautoû árchonta: 491d6), es decir, tal como Sócrates lo entiende, si “dominan en sí los placeres y los impulsos" (tôn hêdonôn kaì epithymían: 491e1)". Esta definición de autogobierno, lejos de satisfacer a nuestro personaje, desata en él el más crudo hedonismo: acogerla, dice, sería llamar sabios a los imbéciles (toû helithíous) y olvidar que nuestro explanandum es "lo bello y lo justo según la naturaleza (tò katà phýsin kalòn kaì díkaion: 491e7)". Según nuestra naturaleza, "para vivir bien, hay que alimentar en ella las pasiones más fuertes, en vez de reprimirlas" (491e9). Por no estar ello a su alcance, la multitud pretende que "la intemperancia es vergonzosa (aischrón)" (492a5). Contra tales "convenciones humanas, contrarias a la naturaleza (tà parà phýsin synthêmata anthrôpôn)" y "dignas de nada (oudenòs áxia)" (492c7-8) se levanta el oponente de Sócrates, quien, sin embargo, alaba su valentía y su franqueza, y reconoce que ha "expresado con claridad lo que los otros piensan pero no se atreven a decir" (492d2-3). Resurge entonces sobre todo una exteriorización de la voluntad divina". En realidad, la mitología griega no es clara en cuanto a los motivos de esta acción de Heracles. Todo parece indicar que éste no obró por su propia iniciativa ni por saberse el más fuerte, sino por mandato de Euristeo, quien le envió “con la orden de traerle los preciosos bueyes" de Geriones (P.Grimal (1994) 246; cf. 213). Además, parece que Euristeo mismo le dio esta orden, o bien por otra previamente recibida de los dioses, o por el amor que había entre ellos, puesto a prueba por la ejecución de este mandato (Una tradición recogida en la época alejandrina cuenta que Heracles era amante de Euristeo: cf. P. Grimal (1994: 187).

44. La idea de superhombre u hombre superior (ho béltistos) vuelve más de una vez en los diálogos platónicos. Cf., por ejemplo, Rep. IX, 590 d 1 y 2 , donde éste es contrastado con el esclavo (doúlos), aunque poniendo de relieve, en contra de Trasímaco, las ventajas de que sea "gobernado por un ser divino y sabio (hypò theíou kai phromímou árchesthai: $590 \mathrm{~d}$ 5.)". También Platón cree que es el mejor quien debe arreglar lo peor (cf. 590c-592a).

45. Cf. Rep. V 473 d; Carta VII, 326 b 1-4.

46. Aristóteles, Pol. 1284 a 11 47. J. Tricot (Aristote, La Politique, Paris, J. Vrin, p. 231) usa "surhommes" en su traducción de 1284 a 10.

48. Pol., III, 13, 1284 a 11.

49. Pol. 1284 a 17: “¿Dónde están vuestras garras y vuestros dientes". Cf. Esopo, Fábula 241.

50. Cf. Rep. I 336 b ss, IX 590 d, Leyes IV 714c.

51. Rep. 338 c 3.

52. Menzel (1964) 64.

53. Cf. Rep. 338 d-e.

54. Cf. Menzel (1964: 64).

55. Cf. Rep. 358 b-c. Glaucón quiere saber "la naturaleza de la justicia y la injusticia y los efectos que ambas producen por sí mismas en el alma en que residen" (358b4-5).

56. Menzel (1964: 67).

57. Rep. 359 a 2.

58. Menzel (1964: 68).

59. Rep. 359 b 3.

60. Rep. 359 c 5-7.

61. Gorg. 484 c-d.

62. Cf. W. Jaeger, Paideia (1971:

662, 836).

63. Cf. Gorg. 487 a ss. 
64. Cf. F. Bravo (2007: 102-107)

65. W.K.C. Guthrie $(1971:, 102)$

66. Cf. Menzel (1964: 113)

67. Guthrie (1971: 106). Según G Rensi, citado por Levinson (1953:

471), "el conflicto Sócrates-

Calicles en el Gorgias no es el

conflicto entre dos individuos,

sino uno que ocurre dentro de una

sola mente". E.R. Dodds (1959:

$13 \mathrm{ss)}$ parece aceptar este punto

de vista cuando dice que, por sentir Platón "cierta simpatía po hombres del sello calicliano", su retrato de Calicles "no sólo tiene calor y vitalidad, sino que respira cierto afecto lleno de pesar". 68. Levinson (1953) 472. 69. Wilamowitz-Möllendorf, Platon (1919: I, 208).

70. Cf. Ref. Sof., 173 a 9. 71. A. Gelio, Noches Áticas, libro X, cap. 22

72. Gorg. $495 \mathrm{~d} 5$.

73. Cf. Gorg. $487 \mathrm{c}$

74. Gorg. 481d-e.

75. Menzel (1964) 114

76. En realidad, en Las Fenicias

se enfrentan los dos puntos

de vista: el iusnaturalism

igualitario de Yocasta, defendido

contra sus hijos Eteocles $y$

Polinice ("la naturaleza -dice-

dio a los hombres la ley de los

derechos iguales (tò gàr íson nómimon anthrôpois: 558), y el iusnaturalismo anti-igualitario de sus hijos (según los cuales "quien ataca tiene el derecho para sí"

258; “los mortales hablan de

igualdad de derechos, siendo asî que éstas no son más que palabras vanas, desmentidas por los actos" (499-502); "si hay un error que pueda justificarse es el que se comete en vista de la realeza,

iniquidad admirable (káliston adikeîn: 524-525)

77. Th. Berg (1872-1877, vol.

IV, p. 447

78. Th. Gomperz (1901: I, 577

cf. la observación similar de A.

Menzel (1964) 114. En cuanto

los rasgos de personalidad, cf. en particular Gorgias 487c

79. Menzel (1964) 115; cf. Gorg.

80. Cf. Gorg. $485 \mathrm{e}-486$

81. Cf. Menzel (1964) 115.

82. Fue, durante la Guerra de Peloponeso, un destacado defensor de la expedición a Sicilia; pero su ansia de poder lo condujo a aliarse con los lacedemonios y los persas.

83. Gorgias $481 \mathrm{~d} 3$ lo presenta como su amante y 519a8 como su amigo.

84. Cf. Gorg. 481d3 y 519a8. 85. Cf. Plutarco, Vidas paralelas, Alcibíades, cap. 34

86. Guthrie (1971) 299. el problema ya debatido con Polo de "cómo hay que vivir (pôs biotéon: 492d5)" y de "quién es dichoso y quién no lo es (hóstis te eudaímôn estín kaì hostis mê: 472c10)". Imposible analizar la abigarrada refutación platónica del hedonismo sibarita de Calicles ${ }^{64}$. En ella se hace patente el abismo que separa lo que es natural según cada uno de los interlocutores: Sócrates lo sitúa en la parte racional del hombre, mientras que Calicles lo coloca en lo irracional.

\section{IV. ¿QUIÉN ES CALICLES?}

¿Pero quién es esta "figura un tanto misteriosa" que no ha dejado "huella alguna en la historia escrita" ${ }^{\prime 65}$ fuera del Gorgias? No hay duda que su identificación puede ayudarnos a entender el modo platónico de filosofar. Reconozcamos, sin embargo, que no hay aún una respuesta satisfactoria a la pregunta planteada ${ }^{66}$. Pese a ello, sería aventurado sostener que el autor "sentía una secreta simpatía por Calicles" y que éste no es, en el fondo, más que "un retrato del yo de Platón que Platón rechaza" ${ }^{67}$. R.B. Levinson observa, con razón, que "no es correcto identificar a Platón con personajes que abomina" ${ }^{\prime 68}$. Fuera de esta hipótesis, que se sitúa en la psicología del subconsciente, hay otras tres, de carácter histórico: (1) Calicles es un personaje histórico tanto en su nombre como en su personalidad; (2) Calicles es un invento de Platón de un extremo al otro; (3) Invento de Platón es su nombre, pero no el personaje como tal, que es históricamente real. La primera, propuesta por Wilamowitz ${ }^{69}$, parece insostenible, pues no hay ninguna referencia a nuestro personaje fuera del Gorgias. Es verdad que Aristóteles lo menciona como defensor de la antítesis nómos-phýsis ${ }^{70}$ y que Aulo Gelio ${ }^{71}$ lo cuenta entre los enemigos de la filosofía; pero ambos se refieren, no a un personaje histórico, sino al dramático del diálogo platónico. Se podría alegar que Platón se refiere a varios hechos que parecen implicar su existencia: a su patria (Acharneus ${ }^{72}$ ); a tres de sus amigos (Androtión, Lisandro y Nausíci$\operatorname{des}^{73}$ ), que existieron realmente; y a Demos, hijo de Pirilampo, que habría sido amante de Calicles $^{74}$. Pero recordemos, con Menzel, que Platón es filósofo y poeta, y que, gracias a su doble talante, ha podido combinar hechos reales y ficciones ${ }^{75}$. Hay que descartar igualmente la hipótesis de que Calicles es un invento puro y simple de Platón, pues sus doctrinas trascienden el Gorgias y han sido compartidas por otros escritores bien conocidos. Por Píndaro, ya referido; por Eurípides, quien desarrolla las mismas doctrinas que Calicles en Las Fenicias ${ }^{76}$; y sobre todo por Tucídides, como veremos luego. Queda la tercera hipótesis, que es objeto de nuevas discusiones.

¿Quién se esconde tras el inventado nombre de Calicles? Algunos historiadores como Theodor Berg $^{77}$ lo identifican con Caricles, uno de los Treinta Tiranos. Pero Th. Gomperz observa oportunamente que fuera de esta similitud onomástica, puramente externa, Platón atribuye a su personaje rasgos de personalidad ajenos a Caricles ${ }^{78}$. Recordemos, con Menzel, que nadie ha mencionado las actividades literarias de este tirano, mientras que Sócrates presenta a Calicles como a uno de los hombres más cultos de la época ${ }^{79}$. Recordemos la espontaneidad con que recurre a Píndaro en apoyo de su iusnaturalismo, y a Eurípides para ilustrar su distinción entre dos géneros de vida ${ }^{80}$. Se podría alegar que también Caricles defendía la tesis del derecho del más fuerte, pues la ejercía en tanto miembro de un gobierno tiránico. Pero lo defendía más en el nivel del ejercicio político que en el propiamente doctrinal. Por razones similares se ha rechazado la sugerencia de 0tto Apelt de que Calicles no es otro que Alcibíades ${ }^{81}$. Éste tenía, ciertamente, una índole dominadora $^{82}$ y era, además, como nuestro personaje, amigo de Sócrates ${ }^{83}$; pero, pese a su fama de orador, no se sabe que haya exhibido aficiones literarias. Además, Alcibíades se hallaba presente cuando el discurso de Calicles $^{84}$, y esto descarta eo ipso la posibilidad de que se identifique con él. Añádase, con Menzel, que Calicles "era un decidido defensor del pensamiento oligárquico y sentía un profundo desprecio por la masa de los débiles", mientras que Alcibíades pretendía apoyar sus planes en el favor del pueblo ${ }^{85}$.

Descartados Caricles y Alcibíades, varios historiadores lo identifican con Critias, quien, según Guthrie, "parece acomodarse exactamente al papel de Calicles" ${ }^{\prime 86}$. Sobre todo Menzel, no duda de que éste es la "la personificación del tío de Platón" y de 
que "la teoría del superhombre está tomada de sus escritos $^{\prime{ }^{87}}$. Antes de él, sólo Christian Cron ${ }^{88}$ había asomado tal hipótesis, pero con argumentos que a Menzel le resultaron poco convincentes. ¿Cuáles son los suyos? Este intérprete distingue entre los argumentos y los "indicios". El primer indicio de que Calicles es Critias sería que el primero aparece como anfitrión de Gorgias ${ }^{89}$, maestro de Critias: tal presentación sería una manera de insinuar su presencia mental en el debate. En la misma dirección apuntaría el hecho de que Calicles sea presentado como amigo de Sócrates ${ }^{90}$ : también Critias lo fue, aunque mal amigo y mal discípulo, a decir verdad, pues se unió al maestro y se separó de él por meras ambiciones políticas $^{91} \mathrm{y}$, con su conducta posterior, dio a sus enemigos (principalmente a Polícrates ${ }^{92}$ ) armas para que le acusen de corromper a la juventud ${ }^{93}$. Un tercer indicio sería que, teste Jenofonte ${ }^{94}$, Critias da a Sócrates los mismos consejos que Calicles en el Gorgias (490c, e): "tendrás que evitar -le dicetus tópicos favoritos: los zapateros remendones, los constructores, los que trabajan los metales". Además -cuarto indicio- Jenofonte alude a la pasión de Critias por Eutidemo ${ }^{95}$, que hace pensar en la de Calicles por Demos, hijo de Pirilampo ${ }^{96}$. En fin, al explicar su concepción de la vida, nuestro personaje cita el Antiope de Eurípides ${ }^{97}$, tal vez para evocar la estrecha amistad entre Eurípides y el tío de Platón ${ }^{98}$. Pero más allá de estos indicios, invoca varios argumentos propiamente dichos. Estos se centran en la personalidad de Critias y Calicles, en las convicciones políticas de ambos y en la producción literaria del primero. (1) Rasgos comunes de personalidad Uno de éstos vendría dado por las tres cualidades que son necesarias para juzgar si alguien vive bien o mal: el saber, la benevolencia y la franqueza (epistêmên te kaì eúnoian kaì parresían ${ }^{99}$ ), que Sócrates descubre en Calicles. Gran número de atenienses pueden testimoniar que es un personaje muy instruido (487b6). Además, es benevolente para con Sócrates (487b8), aconsejándole, movido por la amistad, que abandone la filosofía tal como él la concibe y la practica ${ }^{100}$. Critias hará algo parecido cuando se halle en el poder, aunque no aconsejándole, sino prohibiéndole que imparta su enseñanza ${ }^{101}$. En fin, la franqueza de Calicles le ha permitido "expresar sin ambages lo que los otros piensan, pero no se atreven a decir" (492d2-3). Estas cualidades caracterizaban también a Critias, quien "participaba en las reuniones filosóficas, siendo considerado como profano entre los filósofos y como filósofo entre los profanos" ${ }^{102}$. Filóstrato dice que "gozó de una educación inmejorable" ${ }^{\prime 103}$ y Platón asegura, en el Timeo (20a5), que "no es novicio en nada de lo que nos ocupa". Otra cualidad común a los dos personajes fue la valentía. Calicles sostiene que quienes gobiernan "no son sólo inteligentes (phrónimoi) sino también valientes (andreîoi), pues son capaces de ejecutar lo concebido y no retroceden ante las dificultades de la tarea" ${ }^{104}$. Critias dijo lo mismo con sus obras, pues, luchando contra los demócratas, "murió a manos de Trasíbulo y sus partidarios" ${ }^{105}$. Se le ha reprochado, es cierto, su crueldad. Según Filóstrato, “fue el más perverso entre todos los hombres que hayan alcanzado fama por su maldad" ${ }^{106}$; y según Jenofonte, fue, "entre todos los oligarcas, el más falso, el más violento y el más criminal" ${ }^{107}$. Él y Caricles han sido, entre los Treinta, responsables de numerosas ejecuciones. Pero Critias se justifica diciendo que "una crueldad bien usada (...) es la que se emplea para nuestra propia seguridad, procurando, en cuanto sea posible, que se convierta en útil para el pueblo"108 ${ }^{108}$ (2) Convicciones políticas comunes. Los dos personajes fueron adversarios declarados de la democracia. Para Critias, la democracia es el gran enemigo de la oligarquía: “cuando descubrimos algún enemigo de la oligarquía -confiesa- usamos de todo el poder para apartarlo de nuestro camino. Ningún término medio es posible". Filóstrato cuenta que, de hecho, “colaboró con los espartanos con un tesón inaudito, a fin de que el Ática [bastión de la democracia] fuese despoblada de seres humanos y quedase como tierra de pastos para el ganado" ${ }^{109}$. (3) En cuanto a la producción literaria de Critias $^{110}$, conviene destacar: (a) su gusto por las “expresiones y pensamientos categóricos" ${ }^{\prime 11}$, que agradan igualmente a Calicles; (b) sus estrechos vínculos con Eurípides ${ }^{112}$, comparables con la constante atención de Calicles a este poeta trágico ${ }^{113}$ y a Píndaro, uno de sus más grandes inspiradores. A estas semejanzas literarias se añaden, por asociación, otro rasgo común a los dos personajes, a saber, la inconsistencia en la
87. Menzel (1964) 115. 88. Ch. Cron (1870), cit. por Menzel.

89. Gorg. $447 \mathrm{~b} 8$.

90. Gorg. 487 d.

91. Jenof., Mem., I, 2: “La ambición fue el verdadero motivo de su vida". La ruptura con Sócrates se produjo cuando éste le acusó de ser "semejante a un cerdo, pues deseaba restregarse contra Eutidemo como los cerdos contra las piedras" (Jenof., Mem. I, 2, 12 ss). Jenofonte añade que "por esta razón, Critias odiaba a Sócrates", y así, al llegar a formar parte de los Treinta, "se acordó de él y le prohibió enseñar el arte de discutir".

92. Cf. J. Humbert (1930).

93. Jenof., Mem. I, 2.

Refiriéndose a Critias y Alcibíades dice Jenofonte que "nadie como ellos inflingió tantos males al Estado. Porque Critias fue el más ladrón, violento y asesino durante la oligarquía; mientras que Alcibíades fue el más libertino, insolente y violento durante la democracia".

94. Jenófanes, Mem., I, 2, 37. 95. Jenofonte, Mem., I, 2, 29 96. Cf. Gorg. 481 d 5, 513 b 6. 97. Cf. Gorg. 484e, 485e ss.

98. La amistad entre los dos ha podido inclinar a algunos especialistas recientes a atribuir el fragmento del Sísifo, no a Critias, como Sexto Empírico (Adv. Math. IX, $54=$ DK, 88 B 25) y la tradición posterior, sino a Eurípides, quien también ha escrito un Sisifo, ahora perdido. Cf. Albrecht Dihle (1977) y Ch. Kahn (1997: 247-262).

99. Gorg. 487 a 2-3.

100. Cf. Gorg. 484c.

101. Cf. Jenof., Mem., I, 2, 12 ss. 102. Escol., ad 1.

103. Filóstrato, Vita. Sofistarum.

I, 16 .

104. Gorg. 491b 2-4.

105. Filóstrato, Vitae sophistarum., I, 168

106. Filóstrato, Vit Sophistarum., I, 16 .

107. Jenof., Mem., I, 2, 12.

108. Menzel (1964) 118.

109. Filóstrato, Vit. Soph.,I, 16. 110. Sus obras más importantes son las Elegías, las Constituciones (en verso y en prosa; entre las últimas destacan la de los tesalios y la de los espartanos), los Aforismos, las Homilias y las Tragedias (entre las cuales destaca el Sísifo).

111. Cf. Filóstrato, Vit. Soph. II, 16 .

112. De él cita esta frase en el Tennes: “Ay, no existe ningún 
conducta y el pensamiento. Calicles, prisionero de su doble amor, el Demos ateniense y Demos, hijo de Pirilampo, no tiene, pese a su talento (kaíper ontos deinoû: 481d7), la fuerza para decir "no" cuando hay que hacerlo, y se deja "llevar de un lado a otro (ánô kai kátô metaballoménon: 481e1)", a merced del reclamo de sus amados. Sócrates le reprocha “no decir nunca dos veces lo mismo sobre el mismo objeto" (oudépote tautà legéis perì tôn autôn: 491b8). Los "mejores y más poderosos", por ejemplo, son unas veces los "más fuertes (ischyrotérous)" y otras los "más sabios" (phronimôtérous) (491c1-2). Y en materia hedónica, tras sostener que todos los placeres son igualmente buenos, súbitamente acusa a Sócrates de hablarle "como si no supiera -dice- que ni yo ni nadie olvidamos distinguir entre los placeres mejores y peores (hôs men ... beltíous hedonás, tàs dè cheírous: 499b7). Esta volubilidad, lógica y conductual, se repite en Critias, quien empieza acudiendo a Sócrates y acogiendo su enseñanza ${ }^{114}$ y luego, en cuanto él y Alcibíades se creen "superiores a sus compañeros", "se apartan de él para dedicarse a la política, única causa de su trato con el maestro" ${ }^{115}$. Igualmente incoherente fue en relación con el régimen político: entre los tesalios, "intentó establecer la democracia y armó, con tal fin, a los "penestas" contra los dueños" ${ }^{116}$; en Atenas, en cambio, "estableció la tiranía y fue uno de los Treinta" ${ }^{117}$.

Es indudable que los indicios y los argumentos 121. Gorg., $507 \mathrm{e} 4$ 122. Gorg., 472e7, 525b5. 123. Gorg. 508a1. 124. W.K.C. Guthrie (1971) 84 ss. 125. M. Untersteiner (1967: II, $189 \mathrm{ss})$.

126. Este tipo de política ha tenido un notable desarrollo en la época moderna, siendo su precursor más importante N. Maquiavelo, sobre todo en El Principe. Según él, la única preocupación de un príncipe debe ser buscar y retener el poder, sin que importen consideraciones éticas o religiosas. En el siglo XX Otto von Bismarck acuñó para esta postura el término de Realpolitik. Sobre el concepto de "realismo político", ver L.R. Oro Tapia (2009: 15-46). Sobre los desarrollos y la vigencia de esta corriente, ver R.A. Sanhuesa Carvajal (on line). 127. Cf. Bravo, (2001) 239. 128. Cf. M. Untersteiner (1967) II, 189-232.

129. Cf. Tucid., V, 85-111. aducidos por Menzel, que he comentado libremente, vuelven plausible la identificación de Calicles con Critias. Ayudan, además, a resolver el inquietante problema de la indeclinable deferencia de Platón para con su tío: nunca se le enfrentó directamente y le confirió siempre sitiales de honor, pero no dejó de tener en la mira sus errores. Al personificarlos en Calicles, habría encontrado una buena manera de denunciarlos. Sería, sin embargo, una exageración pretender que Calicles es sólo Critias, como opina Menzel. Entre otras cosas, faltan en el discurso de Calicles elementos que son importantes en el pensamiento de Critias y, a la inversa, falta en Critias uno de los rasgos doctrinarios más característicos de Calicles. Me refiero respectivamente al ateísmo del primero y al hedonismo del segundo. Me limitaré al ateísmo critiano. Desde Sexto Empírico se acepta comúnmente que Critias fue el autor del fragmento restante del Sísifo ${ }^{118}$, que contiene la explicación más antigua del origen y la evolución naturalista de la religión. Según ella, Dios es un invento de algún astuto gobernante que aspiraba a que el temor a su presunta omnipresencia alejase el mal e hiciese la vida social más viable. No obstante la importancia que se ha dado a esta hipótesis, Calicles no le presta la menor atención, pese a que el término 'dios' se repite más de una vez en su discurso ${ }^{119}$ y a que Sócrates le habla de la conducta del hombre para con los dioses (peri theoús) ${ }^{120}$, sosteniendo que el desenfrenado "no puede ser amado" ${ }^{121}$, sino, por el contrario, "castigado por (ellos)" ${ }^{\prime 122}$. Como si estas alusiones a la divinidad no bastaran, Sócrates llega a hablarle en estos términos: "los sabios dicen, Calicles, que el cielo y la tierra, los dioses y los hombres, están unidos por la amistad, el respeto y el orden, la moderación y la justicia, y por eso llaman al universo el orden de las cosas, y no el desorden ni el desarreglo" ${ }^{123}$. Se diría que, pese a que Sócrates le ha incitado a tomar postura ante lo divino, en ningún momento ha dado Calicles signos de compartir el ateísmo de Critias. Sería un signo de que no hay una ecuación entre él y el tío de Platón, ni entre él y personaje histórico alguno, y que lo que el autor del Gorgias quiere representar en él no es un personaje histórico, sino una postura político-filosófica en voga.

Podríamos denominarla, con Guthrie ${ }^{124}$ y Untersteiner ${ }^{125}$, "realismo político". Por tal se entiende la acción política basada en intereses prácticos más que en teorías y principios éticos ${ }^{126}$. Esta postura, incubada durante la Guerra del Peloponeso, se expresa con fuerza singular en Tucídides ${ }^{127}$, pero también en los fragmentos filosóficos de Critias, Licofrón, Alcidamas de Elea y Trasímaco de Calcedonia ${ }^{128}$, y en las obras literarias de Píndaro y Eurípides. Recordemos la discusión entre los enviados de Atenas y los representantes de Melos, una isla que Atenas quería federar por la fuerza ${ }^{129}$. Los atenienses empiezan previniendo que, para zanjar el conflicto que los separa, no esgrimirán argumentos morales, pues saben, al igual que los melios, que, "en el mundo de los hombres, los argumentos de derecho sólo tienen peso en la medida en que los adversarios disponen de medios de coacción equivalentes y que, de no ser así, los más fuertes sacan de su poder el mejor 
partido, mientras que los débiles no tienen más que inclinarse" (V, 89). No se atendrán, pues, la justicia (tò díkaion), sino al interés (tò xymphéron). Pero no al interés mutuo, sino al del más fuerte, que es Atenas. Los melios constatan con sorpresa que "la justicia no tiene nada que hacer en la presente discusión" y que sólo cuentan "las consideraciones de utilidad". No descartan empero "la posibilidad, para quienquiera que esté en peligro [y los atenienses pueden estarlo], de apelar al sentido moral y a la equidad" (V, 90). Pero los atenienses ratifican que lo único que los ha llevado allí es "el bien de nuestro imperio" ( $V$, 91); si parecen interesarse por "salvar" a Melos, sépase que lo único que quieren "salvar" son los "impuestos" que éste puede pagar ( $V$, 92). Y como los melios, como último recurso, confían en que "los dioses no permitirán" verlos desfavorecidos, sus adversarios recuerdan que también los dioses "obedecen, por necesidad natural (hypò phýseôs anankaion), a una ley que les empuja a dominar a los otros cada vez que se sienten los más fuertes" (V, 105). Entre los dioses, no menos que entre los hombres, "siempre (...) el más fuerte pone al más débil bajo su férula" (I, 76). Y si los melios llegan a poner su confianza en los lacedemonios, sus aliados, recuerden que “no hay pueblo que esté más flagrantemente inclinado que éste a identificar lo agradable con lo bueno y su interés con la justicia (tà mèn hêdéa kalà nomízontai, tà dè xymphéron díkaion)" (V, 105). Estos pocos fragmentos muestran que el discurso de Calicles no es exactamente un eco de las doctrinas de Critias, sino del realismo político reinante, formulado por primera vez por Tucídides, sobre todo en los discursos de Hermócrates de Sicilia $^{130}$, Pericles ${ }^{131}$ y el demagogo Cleón ${ }^{132}$. Tucídides, por su lado, ha podido inspirarse en la oda de Píndaro e inspirar luego a Eurípides y Critias, uno de los principales representantes del realismo político. Y lo que es aún más importante, ha podido inspirar la prolongada lucha de Platón contra el mismo, primero en el Gorgias, en la persona de Calicles; luego en la República, en el discurso de Trasímaco (336b-354b), secundado por Glaucón (357a-361b); y por último y repetidamente en las Leyes (690c, 714c, 890a). No carecería de sentido decir con algunos intérpretes que en esta rica literatura griega, tamizada por el genio de Platón, se inspiró, a su vez, Nietzsche, uno de los principales representantes contemporáneos del realismo político.

\section{BIBLIOGRAFIA}

BERG, Th., Griechische Literaturgeschichte, 1872-1877.

BRAV0, F., “Quién es y qué enseña el Trasímaco de la República", in Estudios de Filosofía Griega, Caracas, CEP/ FHE, 2001.

“La antítesis sofística nomos-physis”, Ibidem.

“El Gorgias de Platón: ¿anti-hedonista o anti-relativista?", in M. Erler \& L. Brisson (Eds.), Gorgias - Menon. Selected Papers from the Seventh Symposium Platonicum, Skt. Augustin, Academia Verlag, 2007.

CRON, Beiträge zur Erklärung des platonische Gorgias, Leipzig, G.B. Teubner, 1870.

DIHLE, A., “Das Satyrspiel Sisifo”, Hermes 105 (1977) 28-42.

DODDS, E.R., Plato, Gorgias, 0xford, 0xford University Press, 1959.

DÜMLER, F.D., Academica, Huyesen, 1889.

FOUILLÉ, A., Nietzsche et l' immoralisme, 1902.

GOMPERZ, TH., The Greek Thinkers, London, Murray, I, 1901.

GRIMAL, P., Diccionario de mitología griega y romana, Barcelona, Paidos, 1994.

GUTHRIE, W.K.G., The Sophists, Cambridge, CUP, 1971.

HUMBERT, J., Le pamphlet de Policrate et le Gorgias de Platon, Paris, 1930.

JAEGER, W., Paideia, trad. de J: Xirau, México, FCE, 1971.

KAHN, CH., "Greek Religion and Philosophy in the Sisyphus Fragment" Phronesis 42, 3, (1997) 247-262.

KERFERD, G.B., The Sophistic Movement, Cambridge, CUP, 1981.

LEVINSON, R., In Defense of Plato, Cambridge (Mass.), Harvard University Press, 1953.

MENZEL, A., Kalikles. Eine Studie zur Geschichte der Lehre vom Rechte des Starken, Wien und Leipzig, Franz Deuticke, 1922, trad. esp. de Mario de la Cueva, México, UNAM, 1964.

NESTLE, W., Friedrich Nietzsche und die griechische Philosophie, Neues Jahrbuch für die klassische Philosophie 29 (1912).

ORO TAPIA, L.R., “En torno a la noción de realismo político", Rev. Enfoques, vol VII, nº 10 (2009) 15-46.

SANHUESA CARVAJAL, R.A., "El realismo político: ¿un denostado desconocido?", On line.

UNTERSTEINER, M., I Sofisti, Milano, L. Negri, 1967.

WILAMOWITZ-MÖLENDORF, Platon, Berlín, 1919.

Recebido em novembro de 2012, aprovado em dezembro de 2012.
130. Tucid. IV, 60. 131. Tucid., II, 63. 132. Tucid. III, 39,40 